\title{
OS QUILOMBOS E SEUS DIREITOS HOJE: ENTRE A CONSTRUÇÃO DAS IDENTIDADES E A HISTÓRIA*
}

\begin{abstract}
Jan Hoffman French
Duke University

\section{Resumo}

Este artigo, ao enfocar o processo de reconhecimento de uma comunidade do sertão sergipano como remanescente de quilombo, tem como objetivo discutir como os novos conceitos de quilombo, gerados no processo de reconhecimento jurídico, reconfiguram identidades sociais, num diálogo entre a história, a lei e as práticas culturais. Para tal, o presente artigo questiona teorizações dicotomizadoras, que justapõem uma identidade racial, concebida de forma essencializada, a uma identificação étnica instrumentalizadora, pretensamente construída pela comunidade, com a finalidade de obter terra e recursos.
\end{abstract}

\section{Abstract}

This article illustrates that new concepts of quilombo, arising from the process of legal recognition, reconfigure identities through a dialogue between history, law, and cultural practices in a community in the sertão of Sergipe. It challenges dichotomous theorizations that juxtapose essentialized racial identity against instrumental ethnic identification for the purpose of gaining land and resources.

\section{Pallavras-Chave \\ Identidade $\bullet$ Lei $\bullet$ Quilombo $\bullet$ Cultura $\bullet$ Sergipe \\ Keywords \\ Identity $\bullet$ Law $\bullet$ Maroon Communities $\bullet$ Culture $\bullet$ Sergipe}

\footnotetext{
* O presente ensaio foi publicado em inglês em Political and Legal Anthropology Review, volume 25, $n^{\circ} 2$ (Maio 2002) e foi apresentado como comunicação nos congressos de 2001 da Law and Society Association e da Latin American Studies Association (LASA).
} 
lguns dias após eu ter voltado aos Estados Unidos, depois de um ano de trabalho de campo no Brasil, deparei-me com um artigo publicado na primeira página do New York Times (23/01/2001) intitulado "Former Slave Havens in Brazil Gaining Rights." [Antigos Portos Seguros de Escravos Adquirem Direitos]. O local, lia-se, era "Mangal do Barro Vermelho, Brazil" - um povoado no interior do semi-árido nordestino. $\mathrm{O}$ artigo explicava:

"O telefone mais próximo fica a 19 milhas [30 kilometros] de distância e a televisão só chegou em 1998. Por gerações, comunidades de negros pobres como essa, descendentes de escravos que haviam fugido de seus senhores na época do Brasil colônia, permaneceram em cuidadoso isolamento em um interior desprovido de caminhos. Mas agora, mais de um século depois da abolição da escravatura, esses assentamentos, que nos fazem lembrar algo da África, e que são conhecidos como quilombos, estão emergindo, com hesitação, de sua reclusão e pobreza tradicionais. Com o incentivo e encorajamento do governo brasileiro, eles estão agora exercendo pressão para alcançar a posse das terras ancestrais e reafirmando sua cultura ameaçada. Há muito tempo negligenciados pelo resto do Brasil, os quilombos correm o risco de desaparecerem à medida que o mundo moderno passa a envolvê-los."

O mesmo artigo citava um funcionário do INCRA que afirmava: "Depois que as pessoas venceram a vergonha de dizer que eram descendentes de escravos, seu número cresceu de forma surpreendente." Mais de setecentas dessas comunidades rurais negras estão buscando reconhecimento, baseando-se na constituição que, entrando em vigor cem anos após a abolição da escravatura, contém uma cláusula (conhecida como Artigo 68) que garante a posse da terra aos remanescentes das comunidades dos quilombos ${ }^{1}$. Em 2000, depois de doze anos de acirradas disputas, o ex-Presidente Fernando Henrique Cardoso autorizou a Fundação Cultural Palmares,

\footnotetext{
${ }^{1}$ O Artigo 68 do Ato das Disposições Constitucionais Transitórias reza: “Aos remanescentes das comunidades dos quilombos que estejam ocupando suas terras é reconhecida a propriedade definitiva, devendo o Estado emitir os títulos respectivos."
} 
uma agência do Ministério da Cultura $^{2}$, a dar a posse da terra para comunidades que, metaforicamente, vieram a ser chamadas de quilombos ${ }^{3}$.

Descendo o rio São Francisco do lugar da reportagem do New York Times, chegamos em Sergipe aonde também existem remanescentes de quilombo reivindicando a posse de suas terras. O povoado de Mocambo foi assim reconhecido em maio de 1997. Três anos depois, a associação de moradores do Mocambo, que por gerações haviam sido identificados como trabalhadores rurais ou meeiros, recebeu o título de um extenso pedaço de terra pela Fundação Cultural Palmares, em uma cerimônia em Brasília, no mesmo dia que a comunidade descrita pelo New York Times também o recebia. Tendo-os conduzido à posse da terra, e desde então, os membros da associação quilombola do Mocambo vêm publicamente enfatizando sua identidade recém-descoberta, como descendentes de escravos fugidos, e isso eles fizeram por meio de práticas culturais tais como procissões, peças de teatro, e, mais freqüentemente, por meio de uma dança chamada "samba de coco".

Ao escrever o artigo no New York Times o repórter estava pressupondo uma ligação primordial entre as comunidades rurais negras e suas raízes culturais africanas. No entanto, podemos perguntar se o dispositivo constitucional de reconhecimento apenas reivindica as provas de tal conexão ou se seria ele mesmo o agente criador delas. E por quais processos, legais e extra-legais, os conteúdos do Artigo 68 (cláusula dos quilombos) foram negociados? Tomando essas questões como ponto de

\footnotetext{
${ }^{2}$ A Fundação Cultural Palmares é assim chamada por causa do maior e mais famoso quilombo na história do Brasil, caracterizado por um historiador como "um estado africano no Brasil" e por outros como uma "república negra" (Kent 1965), com uma população estimada em 11.000 habitantes e que durou por quase todo o século XVII (Schwartz 1992:123). A história do quilombo de Palmares foi celebrada por escritores e intelectuais do século dezenove, foi apropriada e usada como arma por militantes do movimento negro nos anos setenta, e ocupa hoje um lugar privilegiado na história oficial do Brasil, sendo o vinte de novembro celebrado como o Dia de Zumbi dos Palmares ou Dia da Consciência Negra, em todo o país.

${ }^{3}$ Como Leinad Ayer de Oliveira (2001: 31) lembra, depois do ano de 1888 "todos os quilombos e quilombolas deixaram de sê-lo para serem remanescentes. Quilombos eram aquelas comunidades formadas por escravos fugidos, ou seja, escravos em condição ilegal ... Este seria ...o conceito formulado no seio do regime escravocrata brasileiro, pelas suas elites.... A abolição, nesta perspectiva, teria tirado estes negros da ilegalidade, o que permitiria abandonar o termo quilombo."
} 
partida, o presente ensaio explorará o processo brasileiro de elaboração de leis, seu impacto em práticas culturais e seus efeitos transformadores na cultura e na formação de identidades (Bower, Goldberg, \& Musheno 2001; Collier, Maurer \& SuárezNavaz 1995; Darian-Smith \& Fitzpatrick 1999; Merry 2000). O ensaio começa com a queda de braço sobre a definição e redefinição do Artigo 68, assim como ele foi aplicado e usado por comunidades rurais negras, com a ajuda de antropólogos, advogados, militantes negros e a Igreja Católica. Baseando-me na literatura a respeito da lei em sociedade, que enfoca a natureza intermitente do processo (Coutin 2000; Holston 1991; Santos 1992), sugiro que a lei no Brasil tem uma qualidade prismática, que reflete a contínua negociação extralegislativa a respeito de como a lei opera, incluindo como ela é posta em prática e como ela é vivenciada. As negociações a respeito da lei no Brasil não estão restritas ao congresso nacional, aos tribunais, ou ao palácio presidencial. Sendo assim, mostro na segunda parte que os processos legais e os significados culturais se encontram engajados em uma série, aberta e constante, de negociações. Da mesma maneira que as interpretações do Artigo 68 foram alteradas com seu uso com o passar no tempo, os significados de algumas práticas culturais na comunidade de Mocambo em Sergipe também mudaram. Entre elas, o samba de coco que foi reconfigurado no processo de reconhecimento legal, ou seja, como evidência de uma história oriunda de escravos fugidos, tornando-se um veículo tanto para expressar uma identidade em relação à lei quanto como meio de concretização dos desejos mais profundos de reconhecimento por parte de uma comunidade particular que possuía vínculos com a terra na qual seus membros vivem e trabalham há gerações.

Revisitando a literatura antropológica a respeito das relações entre a elaboração das leis, práticas culturais e a formação de identidades em tais questões, Ana Alonso (1994: 391) assinala que "a etnicidade é em parte um efeito de projetos particularizadores da formação do estado, projetos que produzem formas hierarquizadas de imaginação popular, que assumem graus variados de apreço social, privilégios e prerrogativas diferenciadas dentro de uma comunidade política." Seguindo na mesma direção, Alonso defende um exame das "relações recíprocas entre processos de formação do estado e a etnogênese," concordando assim com a conclusão de Fredrik Barth, o qual sublinhou que em seu influente trabalho anterior, que ele teria subestimado a importância do papel do estado na criação e manutenção de fronteiras étnicas 
(Barth 1994: 20). A isso eu acrescentaria que as transformações culturais são parte integrante do papel do estado na formação e na mudança da identificação étnica e racial, contanto que ela "seja vista como algo dinâmico, algo que seja usado para que as pessoas se adaptem a condições sociais em transformação - e algo que, por sua vez, seja adaptado ... especialmente em situações que exijam uma rápida mudança (Jackson 1995: 18). Em tais contextos, a cultura toma "diferentes formas, intensidades, ênfases e substancialidade, à medida que os indivíduos se reinventam e reagem a uma política e economia mais amplas" (Warren 1992: 201).

\section{Elaboração de Leis e Oportunidades Legais}

Que a aprovação de uma lei não garante sua aplicação e execução é um truismo bem conhecido. Ele não é, contudo, a verdade pura e simples. Quando Artigo 68 foi promulgado como uma provisão transitória na constituição de 1988, havia pouca expectativa de que ela produziria um efeito contundente. Assim explica o funcionário do INCRA citado pelo New York Times: "Quando começamos, pensamos que haveria apenas casos isolados." Como no Brasil a elaboração de uma lei é freqüentemente apenas um ponto de partida inicial para a negociação de seu sentido e prática, a definição do quilombo, com vistas ao seu reconhecimento foi, desde 1988, debatida, reduzida, ampliada e reduzida de novo, permanecendo sempre em fluxo. Na prática, o Artigo 68, que foi incluído na Constituição com a suposição de que os comprovados descendentes de comunidades de escravos fugidos teriam um número bastante limitado, acabou gerando uma lista oficial de 724 comunidades, 42 das quais foram reconhecidas, e 29 das quais receberam títulos de propriedade (18 do governo federal, incluindo Mocambo, as demais de governos estaduais) ${ }^{4}$.

As negociações descentralizadas que produziram tais resultados sempre dependeram de configurações particulares de poder e de sua relação com o conteúdo da lei. Essas negociações que ocorreram ao longo do tempo de uma forma processual,

\footnotetext{
${ }^{4}$ Para uma lista completa e mapas, consultar o website da Fundação Cultural Palmares (www.palmares.gov.br). A Articulação Nacional Provisória das Comunidades Remanescentes de Quilombos, com sede no Maranhão, o estado com o maior número de quilombos, têm criticado esse número como sendo muito baixo.
} 
implicaram setores da população potencialmente afetados pelo Artigo 68, seus mediadores com o governo e elementos dentro do aparato estatal como advogados, juízes, e a polícia. Ao encararmos o processo de elaboração das leis como uma negociação constante, conduzida para além da legislatura e dos tribunais, podemos começar a entender como o significado do Artigo 68, posto em prática como uma forma de política simbólica, pôde moldar e ser moldado, por e com a participação de múltiplas entidades e atores sociais.

Em tais circunstâncias, a lei pode ser vista como prismática, como se cada um dos lados do prisma fizesse a refração de uma interpretação diferente, expressando as demandas de cada uma das comunidades ou grupos que fazem exigências e que a usam e negociam através dela e, assim, alteram-na, apenas para vê-la ser modificada de novo. Em outras palavras, a linguagem de uma lei constitucional como a dos quilombos poderia ser comparada a um raio de luz unificado que passa por um prisma. À medida que este é refratado por suas faces múltiplas, a luz branca é transformada em um arco-íris de cores individuais, da mesma forma que a linguagem aparentemente estável da lei, quando refratada pelas negociações envolvendo seu uso, pode apresentar significados múltiplos. Meu ponto de vista sobre a lei no Brasil como prismática está em consonância com a sugestão de Susan Coutin (2000: 174), de que a lei de imigração nos Estados Unidos (antes de 11.9.01), da maneira como ela é vivenciada por refugiados, pode ser vista como que brilhando intermitentemente; "ela é tão completamente real quanto ausente." No Brasil, a refração prismática das múltiplas interpretações também é instável, e em momentos iniciais ou de transição, quando não está claro se uma lei vai "pegar" ou se uma dada interpretação vai convencer, a lei pode ser vista como brilhando da perspectiva daqueles que lutam para fazer valer um significado determinado. Refletindo sobre o processo legal brasileiro, Boaventura de Souza Santos (1992: 251) observa que a lei na sociedade brasileira é "ao mesmo tempo legalidade e ilegalidade, ideologia e utopia.... ordem e disordem, um olhar restrospectivo e de antecipação, nostalgia e desejo, opressão e emancipação." Não se trata aqui apenas de uma presença igual ou desigual de qualquer um desses pares de elementos, mas sim do grau ou "modo de tal presença ou ausência."

Este processo fica bem claro no debate a respeito da definição legal dos quilombos, o qual com o objetivo de concretizar a distribuição legal das terras, espelha o debate sobre seu significado histórico; ele também pode ser identificado 
nas múltiplas petições que reivindicam o legado de sua realidade histórica desde os primórdios do moderno movimento brasileiro de consciência negra (Anderson 1996: 546). Em princípio e como resultado da promulgação da constituição, alguns funcionários do governo acreditaram que o significado legal dos quilombos seria determinado por provas históricas. Apenas aquelas comunidades que pudessem traçar sua linha genealógica de volta para os escravos fugidos seriam identificadas como quilombos. Outros funcionários, em especial aqueles ligados aos movimentos de consciência negra, procuraram, no entanto, delinear uma noção mais ampla (por vezes até mesmo incluindo comunidades urbanas negras). Em todos os casos, problemas surgiram quase que imediatamente em relação à definição dos quilombos, uma vez que sempre houveram comunidades negras que negaram seus laços diretos com a escravidão, afirmando terem fugido antes de se tornarem escravos. Existiam ainda, por outro lado, grupos de escravos que adquiriram posse de sua terra através de doações de seu senhores ou da Igreja Católica (Baiocchi 1983; Magno da Silva 2000; Vogt \& Fry 1996). Desde o surgimento do Artigo 68 militantes, estudiosos e membros das comunidades passaram, de forma criativa, a sutilmente relativizar a definição estritamente histórica de quilombo, levando à aceitação deste em um sentido quase metafórico, o que abriu espaço legal para que comunidades negras de passado dilatado pudessem reivindicar suas terras. Até certo ponto, essa flexibilidade pode ser ligada à vontade do governo de estabalecer um compromisso com os militantes da reforma agrária, que estavam decepcionados com sua derrota na Assembléia Constituinte em 1987, o que tornou uma reforma agrária abrangente virtualmente impossível. Algumas vozes se fizeram ouvir fazendo menção ao alargamento do Artigo 68 como "uma reforma agrária para negros," uma vez que haviam tão poucas vias disponíveis para a justiça fundiária ${ }^{5}$.

No ano 2000 as normas administrativas da Fundação Cultural Palmares (Portaria No. 40 de 13 de julho de 2000) forneceram as:

\footnotetext{
${ }^{5}$ Como resultado desta perda estratégica por parte dos defensores dos trabalhadores e dos despossuídos, tornou-se mais difícil para os camponeses pobres obter acesso a pequenos terrenos para a agricultura familiar. Isso desembocou no Movimento dos Trabalhadores Sem Terra (MST), que recebeu apoio internacional, que promoveu cerca de 230.000 assentamentos e que conta com dois milhões de membros por todo o Brasil.
} 
"normas que regerão os trabalhos para a identificação, reconhecimento, delimitação e demarcação, levantamento cartorial e titulação das terras ocupadas por comunidades remanescentes de quilombos, de modo geral, também autodenominadas 'Terras de Pretos', 'Comunidades Negras', 'Mocambos', 'Quilomobo', dentre outras demoninações congêneres, como parte do processo de titulação.”

Em outubro do mesmo ano, a Fundação Cultural Palmares distribuiu um documento para os representantes das comunidades de quilombos como preparativo para a Conferência Mundial de Combate ao Racismo, Discriminação, Xenofobia e outras Formas de Intolerância, com a seguinte definição:

"Quilombo é um espaço de liberdade, de acolhida. Significa povoado, união, grupos que possuem identidade étnica, ancestralidade comum. Ao longo dos tempos houve uma distorção conceitual. Atualmente a historiografia redefine o conceito, não se cingindo apenas a fugas mas formas autônomas de viver, com padrão de uso comum. A principal referência histórica é o quilombo de Zumbi dos Palmares, não sendo um modelo padrão." ${ }^{6}$

A ocupação histórica da terra por negros, o cultivo comunitário e a existência de alguma manifestação de "cultura negra," da maneira como ela foi identificada nos estudos antropológicos, haviam se tornado os critérios para o reconhecimento da existência de um quilombo. Na realidade, os antropólogos tiveram uma importância vital na negociação da mudança na interpretação do Artigo 68. Aqueles que anteriormente haviam trabalhado com comunidades negras estavam aprendendo que seus membros estavam menos preocupados com sua "negritude," ou com a história da escravidão, do que com o preenchimento dos requisitos exigidos pela lei para a obtenção da terra.

A noção de existência de uma "comunidade rural negra" se tornou objeto de estudo no começo dos anos oitenta (Almeida 1989; Baiocchi 1983), baseando-se

\footnotetext{
${ }^{6}$ Em geral, há no Brasil uma preferência por "etnia" ao invés de "raça" como termo para definir o tipo de diferença que nos Estados Unidos seria considerada racial. As explicações históricas para tal preferência remontam ao "mito da democracia racial" sobre o qual muito já foi escrito e que gerou um ardoroso debate desde o começo do século vinte (Guimarães \& Huntley 2000; Twine 1998). A decisão de se definir os quilombos em termos étnicos, ao invés de raciais foi tomada em 1994, com a abandono da exigência de provas estritamente históricas de legitimação (French 2003).
} 
nos estudos a respeito do campesinato dos anos sessenta e setenta (Cândido 1964; Queiroz 1976). Esta abordagem produziu estudos antropológicos e monografias que ajudaram a formar o ponto de vista da Associação Brasileira de Antropologia (ABA) a respeito do Artigo 68. Em 1994, a ABA constituiu um Grupo de Trabalho sobre Comunidades Negras Rurais sob a presidência de João Pacheco de Oliveira Filho, o qual, em 1987, havia conseguido firmar um contrato exclusivo entre a ABA e o governo federal, obrigando este último a utilizar-se de antropólogos filiados à ABA como especialistas na redação dos laudos periciais para o reconhecimento oficial de grupos indígenas (Oliveira Filho 1994). Seguindo-se aos encontros do grupo de trabalho, a ABA foi contratada para realizar a mesma tarefa para a Fundação Cultural Palmares em relação aos quilombos. Um dos membro do grupo de trabalho, Eliane Cantarino O’Dwyer, visitou Mocambo em 1996, para combinar a ida de um antropólogo, com vistas a pesquisar a possível condição de quilombo do local. Alguns anos mais tarde, Eliane Cantarino O'Dwyer apareceu citada no Chronicle of Higher Education afirmando como "estando preocupada que uma interpretação estreita demais poderia ferir o espírito da lei, excluindo outros grupos rurais que precisam da terra". Mas, ao mesmo tempo, O’Dwyer explicou que o Artigo 68 “abriu espaço para uma negociação que não existia antes para a população rural. O governo está atento para outras questões, como a da autonomia de um determinado grupo, e não apenas para seus vínculos com a escravidão" (Mooney 1998).

No sistema legal brasileiro, como James Holston observou (1991: 708), há uma certa "disfunção previsível [que] indica um modo mais sistemático de irresolução." Em seu ensaio Holston lida com operações fraudulentas envolvendo propriedades urbanas e com uma "desordem estratégica." Todavia, no contexto de criação de novos direitos e da garantia da terra para populações rurais do nordeste, a mesma "irresolução legal" pode funcionar como calibradora das relações entre os sem-terra e os privilegiados economicamente, permitindo, assim, apontar para fissuras no sistema, fissuras que podem dar uma dimensão produtiva para esta mesma irresolução. A noção de que a lei, que é frequientemente considerada como uma força negativa ou repressora, também pode fornecer aberturas para a emergência de direitos e para a transformação de identidades foi assinalada por E.P. Thompson (1975: 266-267): apesar de "o direito poder ser visto como intermediador e legitimizador das relações de classe existentes," ele pode "por vezes, inibir o poder e oferecer alguma proteção 
para os desprotegidos"; sendo assim, "as diretrizes e categorias legais penetram todos os níveis da sociedade, põem em prática definições, tanto horizontais quanto verticais, dos direitos e do estatuto legal dos homens e contribuem para sua auto-definição ou sentido de identidade."

Da mesma forma que a lei no Brasil é um espaço de negociação e de definições, ela é também um âmbito de negociação de identidade - não apenas na esfera da autoridade, nacional e internacional, mas, de forma mais importante, no nível local, onde a auto-realização está emaranhada com o poder econômico e pessoal. Em países onde o estado é forte e a lei uma força estável é possível ver a lei impondo "imagens de ordem e autoridade" (Ewing 2002); mas em lugares onde a lei não é uma força estável, como no Brasil, mas que, pelo contrário, tem uma qualidade prismática, a aplicação da lei é com freqüência apenas o passo inicial de uma negociação múltipla e contínua. No caso de Mocambo, por exemplo, isso envolveu indivíduos da comunidade, líderes de grupos que resolveram tomar proveito de uma identidade legal recém reconhecida, representantes de três ou quatro órgãos governamentais, proprietários rurais a favor e contra o processo (por razões políticas, pessoais, históricas e morais), organizações não-governamentais, militantes negros, advogados, antropólogos e políticos. Neste espaço de negociação de identidade por meio da lei, as provas da cultura africana ou da cultura negra rural, exigida nas demandas pela posse da terra são traduzidas, pelas comunidades negras, em reconfigurações da cultura local. Tais reconfigurações estão sendo concretizadas tanto de forma instrumental quanto como identificação subjetiva de uma história e herança até então desconhecidas, encobertas ou silenciadas.

\section{Dançando por Terra ou Apenas Dançando?}

As negociações em torno dos sentidos do Artigo 68 podem ser ilustradas por meio da experiência do povoado Mocambo. Em 1992, um conflito entre os moradores de Mocambo e o proprietário rural em cujas terras eles trabalhavam atraiu a atenção tanto de um padre da região quanto de uma freira, que era uma advogada da Comissão Pastoral da Terra (CPT). Em um esforço para resolver o problema, e tendo conhecimento de outras comunidades rurais que estavam pleiteando seu reconhecimento, a advogada propôs aos moradores do Mocambo, em 1993, que se fizesse uma petição para a Fundação Cultural Palmares, tendo como objetivo seu reconhe- 
cimento como remanescentes de quilombo. Esta foi a primeira vez que eles ouviram falar de tal possibilidade. Depois de considerar as dificuldades envolvidas na tentativa de fazer uso de um método tão inaudito como este para se conseguir terra, os moradores de Mocambo resolveram pleitear a condição de remanescentes de quilombo. Isso deu origem a uma campanha para provar aos representantes do governo, e por fim, ao próprio antropólogo que veio conduzir a pesquisa para seu relatório, que a comunidade derivava de um grupo de escravos fugidos. Em um primeiro momento, o governo expressou dúvida, tanto porque a população não possuía registros de seu passado, quanto porque a arquitetura local não se adequava aos padrões da comissão federal de patrimônio. Porém, em 1994, depois que um grupo de famílias do Mocambo ocupou ilegalmente terras vizinhas em disputa, os habitantes do povoado e sua advogada voltaram sua atenção, de novo, para a possibilidade do quilombo. A esta altura, as exigências apresentadas pelo Artigo 68 estavam sendo flexibilizadas, ao menos em parte, devido ao fato dos investigadores do governo e antropólogos terem descoberto que era difícil, por vezes impossível, documentar a existência histórica de comunidades de escravos fugidos. O que estava sendo encontrado em vários lugares eram evidências a respeito de terras cultivadas coletivamente, assim como certas danças, canções e festivais. Com as mudanças na interpretação do Artigo 68, os habitantes de Mocambo se colocaram em uma posição melhor para provar sua condição de remanescentes de quilombo.

As condições de vida dos moradores de Mocambo são muito semelhantes àquelas da maioria da população rural que vive no sertão sergipano e que há gerações sobrevivem como meeiros, bóia-frias, ou que vivem da exígua aposentadoria dos mais velhos. Os sertanejos vivem em pequenos assentamentos (com não mais de 50 ou 100 casas que têm de dois a quatro aposentos) ou em moradias esparsas, por vezes a quilômetros umas das outras. As mulheres tomam conta da casa e das crianças, transportam água retiradas do rios ou córregos das vizinhanças em baldes, carregando-os na cabeça ou a armazenam água das chuvas infreqüentes, plantam e colhem no terreno doméstico. Os sertanejos são em sua maioria católicos, e cada vila ou assentamento tem a sua capela própria. Um padre da região costuma visitar as vilas aproximadamente uma vez por mês, para realizar batizados, casamentos e missas de sétimo-dia. Nem os funerais, nem as missas semanais são conduzidas por padres, que deixam assim essas cerimônias serem praticadas por leigos. A cultura sertaneja 
local está entrelaçada com práticas católicas populares e rurais, que têm séculos de idade, como as orações para os doentes, o uso de ervas e plantas locais para tratar enfermidades, as procissões, antes do raiar do dia, dedicadas aos santos padroeiros, peças sobre a Paixão de Cristo, vários festivais e um complexo sistema de apadrinhamento. Há no vilarejo casas tipicamente sertanejas e igrejas que seguem o modelo medieval português; pratica-se lá também a produção artesanal de cerâmica e corda, redes de pesca e madeira talhada.

Entre as práticas culturais que marcam a cultura popular do nordeste rural encontra-se uma grande variedade de danças, como, por exemplo, o samba de coco, cuja origem, imagina-se, tem raízes africanas. O samba de coco é acompanhado por canções, por um bater de palmas simples, e pelo bater de cascas de coco, ou de pés no chão, acompanhando o ritmo da dança. Folcloristas do nordeste como Alceu Maynard Araújo (1964: 239), cuja pesquisa remonta aos anos cinqüenta, chamou o samba de coco de "a dança dos pobres, dos desprovidos da fortuna, daqueles que possuem apenas as mãos para dar ritmo, para suprir a falta do instrumento musical.” A origem do samba de coco foi traçada como oriunda de Alagoas, o estado na outra margem do rio de onde Mocambo se encontra. No entanto, ele pode ser encontrado em todo o Nordeste e Araújo o considera como "afro-ameríndio." A dança pode ter a forma de um círculo, com os solistas se revezando e dançando no centro (como acontece em Mocambo) ou pode ser dançada em pares como uma quadrilha (como na aldeia tribal vizinha, área indígena reconhecida como tal em 1979) (Melo 1982: 63) ${ }^{7}$. Nos anos noventa, as mani-

\footnotetext{
${ }^{7}$ Em 1979, um grupo de famílias aparentadas com os moradores de Mocambo foi reconhecido como grupo indígena - os Xocó. Um entre os mais de trinta grupos reconhecidos no nordeste desde meados dos anos setenta, as pessoas reconhecidas como Xocó haviam dançado o samba de coco até que uma tribo do outro lado do rio, em Alagoas, os ensinou o toré, uma outra dança sertaneja, tida como de origem indígena. No começo do período de acelerados reconhecimentos de tribos, dançar o toré havia se tornado o critério básico usado como prova de descendência indígena. Ele havia se constituído como "expressão obrigatória da indianidade no Nordeste" (Arruti 1999: 255). Os membros das tribos recém-reconhecidas, expressando um fenômeno que não ficou restrito ao nordeste, foram chamadas por Jonathan Warren de "índios pós-tradicionais" em um esforço para sinalizar a falta de práticas culturais originárias entre eles (Warren 2001). Minha tese de doutorado lida com questão da gênese do reconhecimento tribal dos Xocó e com a luta do Mocambo para ser reconhecido como remanescente de descendentes de quilombo em suas interrelações. Meu trabalho procura mostrar também como esta dinâmica tem contribuído para transformar suas identidades em conexão com uma nova lei para cada um dos casos (French 2003).
} 
festações culturais sertanejas, tais como o samba de coco, estavam sendo reconsideradas como provas para o reconhecimento da condição de remanescentes de quilombo. Quando os representantes da Fundação Cultural Palmares e os militantes negros do estado visitaram Mocambo pela primeira vez em julho de 1994, alguns dos habitantes começaram a reconfigurar a dança como evidência de sua história de escravos negros fugidos.

Quando o antropólogo encarregado pela Fundação Cultural Palmares de pesquisar o caso de Mocambo lá chegou pela primeira vez, em 1995, e durante sua segunda visita, em 1996, um grupo de idosas da comunidade e alguns jovens dançaram o samba de coco para ele. Em seu relatório, apresentado em janeiro de 1997, cinco meses antes de ser parcialmente publicado, no Diário Oficial da União, o registro do reconhecimento legal de Mocambo, ele observou que a dança havia sido apresentada a ele três vezes, uma por ocasião de cada visita sua, nos encontros da associação que defendia o reconhecimento do quilombo. A dança era acompanhada por um tamborim que tinha seu ritmo marcado pelo bater de mãos e pelo som do pés de encontro ao chão da casa do paróquia (Arruti 1997: 14). Os mais velhos explicaram a ele que a dança tradicionalmente ocorria em ligação com o trabalho coletivo nas lagoas de arroz, ao longo dos bancos do rio. Na última etapa da colheita, quando a lagoa era "fechada," dançava-se o samba de coco para celebrar.

As canções que acompanhavam o samba de coco eram freqüentemente intituladas de acordo com nomes de cangaceiros, já que Alagoas e Sergipe eram as principais redondezas de Lampião e Maria Bonita (Chandler 1978). Outros temas recorrentes nas canções incluíam o plantio e as relações amorosas. Arruti (1997: 15), em seu relatório, decidiu enfatizar a seguinte canção que acompanhava uma das danças que ele presenciou: "Samba negro, que branco não vem cá; Se vinhé, pau há de levá." Apesar da letra evidenciar uma hostilidade clara contra os brancos, Arruti (2002: 234) relatou que "o sertão [de Sergipe] não possui registros históricos sobre quilombos ou rebeldia escrava correspondente à incidência de tais comunidades no presente." A literatura sobre o folclore do Nordeste, desde os anos 40 (e.g. Ramos 1942), registrou esta letra de música como sendo cantada por toda a região (Melo 1982: 74); sendo assim, é provável que a canção seja parte de uma cultura sertaneja, que inclui muitas referências a temas sobre escravos. Desta forma, a canção, da mesma forma que a dança, foi reenquadrada para fornecer provas de uma história particular. 
Na medida em que "as imagens do passado e o conhecimento rememorado do passado [estavam sendo] transmitidos e mantidos" pela "execução mais ou menos ritualizada" do samba de coco, eles estavam sendo configurados nos anos noventa como prova de um imaginário histórico sobre quilombo (Connerton 1989: 4).

Quando o presidente da Fundação Cultural Palmares chegou em Mocambo, em 1997, para a cerimônia de oficialização do reconhecimento, o samba de coco foi dançado em honra da ocasião. No segundo aniversário do reconhecimento, pude presenciar a dança. No ano seguinte, Severo D'Acelino, um militante do movimento negro de Aracaju que havia participado das discussões iniciais sobre a possibilidade de se buscar o reconhecimento da condição de remanescentes de quilombo, deu um seminário em Mocambo sobre a cultura negra. Foi a partir daí que as mulheres, que sempre haviam dançado com roupas do dia-a-dia, shorts e camisetas, começaram a adotar os trajes das cerimônias religiosas afro-brasileiras, tais como o candomblé-saias, blusas e turbantes, todos brancos. Isso foi o que eu vi quando a dança foi executada de novo no Dia da Consciência Negra, em 2000. Três anos após o reconhecimento, a dança havia sido totalmente transformada em uma representação de uma história de raízes africanas, tendo sido dançada tanto para celebrar o recebimento da terra naquele próprio ano como para convencer aqueles na comunidade que ainda se opunham à condição quilombo, que não era possível voltar atrás (French 2003). O Mocambo havia entrado na consciência da nação como um quilombo e lá haveria de ficar, ao menos se dependesse da associação quilombo local e seus defensores no governo federal, nas ONGs, e na Igreja ${ }^{8}$.

Uma vez que as pessoas em Mocambo tiveram que "provar" uma identidade, que eles há pouco haviam começado a considerar como sendo "deles," a importância de sua dança e até mesmo a maneira como eles trabalhavam a terra passou a ocupar o primeiro plano, mas sempre dentro dos parâmetros de suas próprias vidas. Quando a possibilidade surgiu de se obter a posse legal da terra, na qual eles haviam traba-

\footnotetext{
${ }^{8} \mathrm{Na}$ eleição no começo do ano, o prefeito do município, que desde o começo havia se oposto ao reconhecimento do Mocambo como remanescente de quilombo, havia mudado de idéia e foi reeleito, em parte porque aqueles que apoiavam o quilombo mudaram seus votos. Isso foi uma reviravolta para o grupo de moradores de Mocambo contrários ao reconhecimento deste como quilombo, um grupo que contava com o apoio de aproximadamente um terço da população local.
} 
lhado por tantos anos, a coordenação de práticas culturais adquiriu sentidos que foram incorporados em suas memórias de plantio e dança (Rappaport 1994). Em Mocambo, a transformação do samba de coco de um evento privado e celebratório ligado ao cultivo e ao trabalho, para uma ação pública, "separada e enquadrada," fez dele uma "importante dramatização", que permitiu a seus participantes entender e criticar seu mundo (Guss 2000).

Desde meados dos anos noventa, quando o samba de coco passou a ser associado ao movimento quilombola em Mocambo houveram ocasiões nas quais as forças de oposição e a lentidão do governo para conceder os títulos de posse levaram a uma perda de interesse, ou até mesmo à recusa de se dançar. Como David Guss (2000) observou,

\footnotetext{
“à medida que a questão do "grupo" se torna mais problemática, o problema da interpretação também se torna maior. Ou, em outras palavras: de quem é a realidade que está sendo refletida? A ação ou prática cultural permanecerá, assim, ao mesmo tempo beligerante e ambígua, e ainda que a estrutura básica de um evento possa ser repetida, haverá suficientes mudanças implementadas para redirecionar seu sentido."
}

Zoila Mendoza (2000: 239) também notou que os locais de práticas e ações culturais são frequientemente lugares de tensão, confrontação e contestação. Quando visitei Mocambo pela primeira vez, em 1998, a dança foi executada para mim dentro de uma casa e não na rua, em público, onde a vi acontecer em ocasiões posteriores. Ao retornar, no começo de 2000, a organizadora da dança, Dona Maria, que era também a matriarca de uma das duas principais famílias do movimento quilombo, me disse que nunca mais dançaria o samba de coco. Ela estava se sentindo desencorajada por causa de problemas com a oposição, cujo líder era o seu sobrinho. Assim, uma questão política havia se tornado também uma briga de família, por causa do qual ela, Dona Maria, já há cinco anos, não falava com sua irmã. Dona Maria e outra líder do movimento disseram que suas pernas doíam e que já estavam idosas demais para dançar. No entanto, depois de terem recebido o título de propriedade de suas terras, em julho de 2000, elas dançaram com suas roupas e turbantes brancos e também organizaram um grupo de crianças para fazer sua própria versão do samba de coco no mesmo ano, durante a comemoração do Dia da Consciência Negra. O ir e vir das ocasiões para a execução da dança refletia e marcava alianças políticas locais, relações com o governo e o estado presentes na negociação a respeito do 
significado da lei. Desta vez, elas dançaram no salão comunitário da associação do quilombo (a associação da oposição tem a sua própria casa, separada), que é um grande espaço público usado para festas, encontros, votações, e para assistir aos jogos de futebol em uma das poucas televisões de Mocambo (French 2003).

Como pode ser lido no artigo do New York Times, já se tornou comum usar "cultura" nos Estados Unidos como sinônimo para raça, entendida em termos primordializados como expressando uma diferença inescapável que encontra-se debaixo da superfície, esperando para ser "achada," "reencontrada" ou "preservada." Adotar esta perspectiva levaria a que se considerasse as pessoas de Mocambo, que são objeto de descoberta por parte de estranhos, como sujeitos que "assumem" sua identidade quilombo que por centenas de anos havia estado enterrada sob o manto do "sertanejo." Tal visão, todavia, não leva em conta a complexa interação entre lei, política, profissionalismo, necessidades locais, práticas culturais e realidades econômicas, que se combinam para produzir as comunidades quilombolas legalmente reconhecidas. Poderia ser, assim, mais fácil e simples defender a noção de que uma reivindicação de identidade, como a de descendentes de escravos fugidos, é um exercício de ação meramente instrumentalizadora (Cohen 1974).

É claro que um desejo intenso de possuir a terra e a vontade de se libertar, tanto do trabalho assalariado quanto da política de apadrinhamento da região, são parte do ímpeto que leva à busca de benefícios por meio da adoção de uma identidade cultural que se adequasse às expectativas formuladas recentemente pelo Artigo 68 e suas interpretações cambiantes. A procura de formas para se aliviar deste fardo e para adquirir direitos como habitantes de uma região rural pobre em um ambiente econômico neo-liberal, crescentemente globalizado - um contexto que não tem nenhum interesse neles como trabalhadores, especialmente em áreas onde a terra é pobre e a água escassa - os moradores de Mocambo teriam todas as justificativas para reivindicar certas identidades culturais, étnicas ou raciais.

Pode parecer apropriado adotar uma visão instrumentalista como essa, mas fazer isto equivaleria a negar a evolução dos significados envolvidos no termo remanescente de quilombo para os moradores de Mocambo, que agora reivindicam e lutam por uma identidade de quilombola. $\mathrm{O}$ instrumentalismo como explicação é também desmentido por um terço da população local, que nega a condição quilombo e se recusa a assumir tal identidade. Se é tão útil ser um quilombola, por que há uma fração tão 
significativa da população de Mocambo que, nas palavras de Dona Maria, "são, mas não assumem"? Apenas uma abordagem que leve em conta essas complicações poderá ter realmente um valor explicativo. Além disso, uma perspectiva instrumentalista colocaria o observador em uma postura funcionalista (Sahlins 1999), que deixaria pouco espaço livre para a compreensão da criatividade local, para os significados advindos das histórias, pessoais e do grupo, e para uma ligação emocional como lugar onde vivem, embora tudo isso esteja expresso no processo de luta pelo reconhecimento legal. Finalmente, uma tal interpretação faria do estudioso um possível alvo de argumentos semelhantes aos de um fazendeiro nordestino que, depois de ser acusado de impedir que o bispo e trezentas pessoas realizassem uma missa ao ar livre em sua propriedade, para a comunidade negra, declarou: "Não há prova nenhuma que já houve um quilombo nas minhas terras. Se a minha terra foi um quilombo, então toda a Bahia é um quilombo, porque há negros por todo o estado" (Brooke 1993).

Quando nos confrontamos com ferramentas analíticas empobrecidas e reducionistas, tais como as de heranças culturais primordiais ou de motivações instrumentalistas, surge a seguinte questão: Como honrar as necessidades e desejos do povo de Mocambo e reconhecer a dedicação daqueles que tomaram seu partido sem se renderem a noções reificadas de identidade e cultura, que entravam em conflito com nossa compreensão a respeito da natureza processual da lei, da cultura e da história? (Moore 1978; Starr \& Collier 1989) Defendo que é possível reconhecer o componente instrumental da ação política sem ignorar as especificidades culturais pertencentes a práticas que, em Mocambo, levaram ao reconhecimento legal. Como já foi expresso por Abner Cohen (1993:7), em sua obra sobre o carnaval da Caribe inglês em Londres, publicada vinte anos depois do seu importante trabalho sobre a etnicidade política, as formas culturais "expressam e consolidam os sentimentos e a identidade de pessoas que se agregam em resposta a condições econômico-políticas específicas." Os elementos de cultura, ele continua, podem estar "ligados à ação política; mas o evento em si é uma forma cultural sui generis e não pode ser reduzido ou descartado apenas em termos de política. Uma vez que ele se desdobra, ele se torna uma intervenção, não apenas uma expressão".

Em suma, os dois terços da população de Mocambo que se identificam como quilombola tomaram posse de certos aspectos da cultura sertaneja e os usaram para se adequar às exigências legais. O exemplo de Mocambo mostra, assim, que os movimentos políticos 
podem constituir novas formas de se produzir as diferenças culturais relevantes do ponto de vista organizacional. Como os símbolos culturais trazem significados múltiplos, a ação política pode determinar quais de tais significados se revestem de maior potencial emocional e, particularmente nos casos que envolvem terra, quais significados provocam "representações intuitivas emocionalmente poderosas" de lugar (Levine 1984: 85-86). Afinal de contas, a invocação da “tradição," devido à sua própria natureza, envolve uma dimensão de seletividade, conduzindo assim a uma escolha, quase que imperceptivelmente emocional, mas ainda assim prática, de uma identidade particular (ou da rejeição de tal identidade), em uma situação específica. Assim como a trouvaille de Bourdieu (1977: 79), os sentidos culturais mobilizados em ocasiões determinadas podem parecer como "uma simples escavação, ao mesmo tempo acidental e irresistível, de uma possibilidade enterrada.” Este sentido de uma escavação irresistível ressoa nas formas com que os preceitos primordialistas se tornam, por vezes, "entrelaçados com a consciência e a prática política" (Hale 1997: 578). Ainda que a etnicidade possa ser "o produto de processos históricos específicos, ela tende, de fato, a assumir a aparência de uma força autônoma e 'natural,' um 'princípio' capaz de determinar a direção da vida social" (Comaroff \& Comaroff 1992: 60). Consequentemente, ao reconhecermos que os signos e os símbolos de identificação podem funcionar tanto para invocar profundos sentimentos de ligação com um lugar, como para servir a um fim politicamente emancipatório, nos colocamos em uma posição mais satisfatória para eliminar o abismo existente entre primordialismo e instrumentalismo.

\section{Conclusão}

Em meados de 2001, a transformação de uma visão histórica do conceito de quilombo para uma metáfora de luta moderna por direitos já havia ocorrido. Escrevendo em 2001, o antropólogo que havia preparado o relatório sobre Mocambo, observou que "os quilombos deixaram de ser apenas um fato histórico, uma data de comemoração da resistência negra no passado. Hoje cada comunidade negra rural é vista e passa a se ver também como um quilombo, que ainda resiste e luta pelo direito de estar em suas terras e de viver do seu modo" (Koinonia 2001b: 4). Os quilombos, em meados de 2001, deviam ser definidos como "todas as comunidades negras rurais mobilizadas pela legalização de suas formas de uso comum da terra" (Koinonia 2001a: 3). No entanto, justamente quando a interpretação do Artigo 68 
parecia ter se estabilizado, os acontecimentos tomaram uma nova direção e seus resultados se farão sentir em negociações futuras. Em setembro de 2001, o então presidente Fernando Henrique Cardoso emitiu um decreto (no. 3.912) extremamente restritivo. Ele reintroduziu a exigência de provas históricas para o reconhecimento de comunidades oriundas de quilombos, o que viria a reduzir seu número ${ }^{9}$. Este decreto determinava que só poderiam ser reconhecidas as comunidades que comprovassem que existiam como quilombos no ano da abolição da escravatura, e que ainda fossem habitadas por seus descendentes cem anos depois, isto é, no dia 5 de outubro de 1988, data da Constituição ${ }^{10}$.

Esta mudança de rumo por parte do ex-presidente pode ter sido o resultado de problemas surgidos depois que os primeiros títulos de propriedade de terra foram concedidos pela Fundação Cultural Palmares, em julho de 2002, sem ter havido a prévia expropriação ou compensação dos proprietários existentes. Tais concessões, incluindo a de Mocambo, deixaram em seu rastro, uma série de questões legais que estão ainda sendo resolvidas pelos advogados do governo, já há mais dois anos. Mais ainda, a natureza das provas históricas que serão necessárias para se comprovar a existência de um quilombo e um século de ocupação subsequente ainda é objeto de controvérsia no interior do Brasil, onde registros de terra são freqüentemente inexistentes ou fraudulentos. A Igreja Católica pode ser útil em algumas áreas de averiguação, como

\footnotetext{
${ }^{9} \mathrm{O}$ estatuto legal das medidas provisórias, adotadas em substituição à legislação do congresso nacional, é uma questão muito debatida entre os juristas brasileiros. Queixas abundam sobre o uso abusivo, pelo ex-presidente Fernando Henrique Cardoso, de seus poderes emergenciais para extender decretos por anos após sua data de expiração prevista.

${ }^{10}$ Em uma entrevista com o presidente da Fundação Palmares, Carlos Alves Moura, em abril de 2002, fui informada de que ele não tinha nenhuma intenção de pôr em prática essa parte do decreto, e que ele estava redigindo um pedido ao então presidente Cardoso para revisá-lo, de forma a remover este parágrafo. A explicação de Moura para a inclusão de tal cláusula era que o presidente Cardoso desejava evitar ter de indenizar os proprietários de terra, mas Moura salientou que este objetivo não era realista. Até agora não sabemos se e como esta posição pode mudar com a nova liderança na Fundação Cultural Palmares e a nova presidência de Lula. No dia 13 de maio de 2002, no Despacho do Presidente No. 370, o então presidente Cardoso vetou integralmente "por inconstitucionalidade e contrariedade ao interesse público" a versão final do Projeto de Lei (129/95 e 3.207/97) na Câmara dos Deputados, relativo ao Artigo 68, que estava sendo debatido desde 1995, deixando em vigor Decreto no. 3.912 de 10 de setembro de 2001.
} 
nos registros de batismo que se referem à época da escravatura; mas a negociação dessas e de outras questões legais é uma tarefa para o futuro, especialmente com o novo governo de Lula, que sem dúvida imprimirá interpretações diferentes, assim como envolverá atores e comunidades diferentes - uma situação que, mais uma vez, aponta para a qualidade prismática da lei e de sua elaboração no Brasil ${ }^{11}$.

Em Mocambo, as práticas culturais estão tanto sendo reconfiguradas e mantidas em novas formas, como estão sendo cercadas de novos discursos, que revelam modos de formação e ação política autônomas. Contudo, esta pesquisa não deve terminar aqui. Tendo em mente o estado boliviano e a etnicidade indígena, antropólogo Thomas Abercrombie (1991: 99) argumenta que quaisquer que sejam os significados que possam se juntar à determinada forma de cultura dita tradicional, eles "são hoje produzidos e interpretados dentro dos sistemas semióticos (semi-abertos) produzidos em lugares interculturais específicos, localmente, ou de acordo com situações próprias... que se entrecruzam com sistemas nacionais e internacionais, de forma tão significativa como com grupos da cidade vizinha." Nesse ensaio sugeri que a maneira como as exigências, interesses e desejos da sociedade como um todo se manifestam nas leis, nos discursos de seus elaboradores, dos acadêmicos e dos meios de comunicação são partes integrantes, necessárias para uma compreensão dos processos de elaboração de leis e resignificação das práticas culturais que se entrelaçam com significados legais. Sendo assim, a reconfiguração das práticas culturais em uma região semi-árida, distante e esquecida, pode nos levar a investigar, e até mesmo a começar a entender, grupos sociais mais amplos, nacionais e internacionais, que consideram tais práticas culturais importantes o suficiente para trazê-las à primeira página do New York Times.

\footnotetext{
${ }^{11}$ Em maio de 2003, o governo de Lula anunciou que o programa Fome Zero vai atender 14 mil famílias em 142 comunidades remanescentes de quilombo. "A idéia é distribuir o cartão-alimentação e cestas básicas ... além de providenciar certidões de nascimento, incentivar a produção agrícola, de artesanato e regularizar a posse de terras nas quais vivem descendentes de escravos fugidos" (O Estado de S.Paulo, 14 de maio de 2003).
} 


\section{Referências Bibliográficas}

ABERCROMBIE, Thomas. "To Be Indian, to Be Bolivian: Ethnic and National Discourses of Identity." In URBAN, Greg and Joel Sherzer. Indians and Nation-States in Latin America. Austin: University of Texas Press, 1991, 95-130.

ALMEIDA, Alfredo Wagner Berno de. "Terras de Preto, Terras de Santo, Terras de ÍndioUso Comum e Conflito, na Trilha dos Grandes Projetos." In Castro and Hebette. Cadernos Naea 10, Belém: Gráfica e Editora Universitária UFPA, 1989, 163-96.

ALONSO, Ana María. "The Politics of Space, Time and Substance: State Formation, Nationalism, and Ethnicity." Annual Review of Anthropology 23 (1994): 379-405.

ANDERSON, Robert N. "The Quilombo of Palmares: A New Overview of a Maroon State in Seventeenth-Century Brazil.” Journal of Latin American Studies 28 (1996): 545-66.

ARAÚJO, Alceu Maynard. Folclore Nacional: Danças, Recreação, Música. Vol. II. São Paulo: Edições Melhoramentos, 1964, 460 p.

ARRUTI, José Maurício Andion. Mocambo de Porto da Folha: Parecer HistóricoAntropológico Solicitado pelo Projeto Quilombos - Terras de Preto do Centro de Estudos sobre Território e Populações Tradicionais para o Convênio Cett/Ministério da Cultura (N. E132/96-Se), 1997.

ARRUTI, José Maurício Andion. “A Árvore Pankararu: Fluxos e Metáforas da Emergência Étnica no Sertão do São Francisco.” In PACHECO DE OLIVEIRA, João. A Viagem da Volta: Etnicidade, Política e Reelaboração Cultural no Nordeste Indígena. Rio de Janeiro: Contra Capa Livraria, 1999, 229-78.

ARRUTI, José Maurício Andion. “"Etnias Federais': O Processo de Identificação de 'Remanescentes' Indígenas e Quilombolas no Baixo São Francisco.” Tese de Doutorado, UFRJ, 2002.

AYER DE OLIVEIRA, Leinad. "Sobre as Datas e as Competências no Decreto No. 3912/ 2001.” In AYER DE OLIVEIRA, Leinad. Quilombos: A Hora e a Vez dos Sobreviventes. São Paulo: Comissão Pró-Índio, 2001, 30-33.

BAIOCCHI, Mari de Nasare. Negros de Cedro (Estudo Antropológico de um Bairro Rural de Negros em Goiás). São Paulo: Ática, 1983, 201 p.

BARTH, Fredrik. “Introduction.” In Barth, Fredrik. Ethnic Groups and Boundaries: The Social Organization of Culture Difference. Boston: Little, Brown and Company, 1969, 9-38. 
BARTH, Frederik. "Enduring and Emerging Issues in the Analysis of Ethnicity." In VERMEULEN, Hans and Cora Govers. The Anthropology of Ethnicity: Beyond 'Ethnic Groups and Boundaries.' The Hague: Het Spinhuis, 1994, 11-32.

BOURDIEU, Pierre. Outline of a Theory of Practice. Translated by Richard Nice. Cambridge: Cambridge University Press, 1977, 248 p.

BOWER, Lisa C., David Theo Goldberg, and Michael C. Musheno. Between Law and Culture: Relocating Legal Studies. Minneapolis: University of Minnesota Press, 2001, 337 p.

BROOKE, James. "Blacks Seek to Return Ancestral Lands to Descendants of Fugitive Slaves." The New York Times, August 15, 1993, 9.

CÂNDIDO, Antônio. Os Parceiros do Rio Bonito; Estudo sôbre o Caipira Paulista e a Transformação dos Seus Meios de Vida. Rio de Janeiro: J. Olympio, 1964, 239 p.

CHANDLER, Billy Jaynes. The Bandit King: Lampião of Brazil. College Station and London: Texas A\&M University Press, 1978, 262 p.

COHEN, Abner. "Introduction: The Lesson of Ethnicity." In COHEN, Abner. Urban Ethnicity. London: Tavistock Publications, 1974, 391 p.

COHEN, Abner. Masquerade Politics: Explorations in the Structure of Urban Cultural Movements. Berkeley: University of California Press, 1993, 166 p.

COLLIER, Jane F., Bill Maurer, and Liliana Suárez-Navaz. "Sanctioned Identities: Legal Constructions of Modern Personhood." Identities: Global Studies in Culture and Power 2, no. 1-2 (1995): 1-27.

COMAROFF, Jean, and John Comaroff. "Of Totemism and Ethnicity.” In Comaroff, Jean and John Comaroff. Ethnography and the Historical Imagination. Boulder: Westview Press, 1992, 49-67.

CONNERTON, Paul. How Societies Remember. Cambridge: Cambridge University Press, 1989, $121 \mathrm{p}$.

COUTIN, Susan Bibler. Legalizing Moves: Salvadoran Immigrants' Struggle for U.S. Residency. Ann Arbor: University of Michigan Press, 2000, 228 p.

DARIAN-SMITH, Eve, and Peter Fitzpatrick. Laws of the Postcolonial, Law, Meaning, and Violence. Ann Arbor: University of Michigan Press, 1999, 309 p.

EWING, Katherine Pratt. "Migration, Identity Negotiation and Self Experience.” In FRIEDMAN, Jonathan. Globalization and Cultural Security. London: Taurus, 2002.

FRENCH, Jan Hoffman. "The Rewards of Resistance: Legalizing Identity among Descendants of Índios and Fugitive Slaves in Northeastern Brazil.” Tese de Doutorado, Duke University, 2003. 
GUIMARÃES, Antônio Sérgio Alfredo, and Lynn Huntley, eds. Tirando a Máscara Ensaios sobre Racismo no Brasil. São Paulo: Editora Paz e Terra, 2000, 434 p.

GUSS, David M. The Festive State: Race, Ethnicity, and Nationalism as Cultural Performance. Berkeley, Calif.: University of California Press, 2000, 239 p.

HALE, Charles R. "Cultural Politics of Identity in Latin America." Annual Review of Anthropology 26 (1997): 567-90.

HOLSTON, James. "The Misrule of Law: Land and Usurpation in Brazil." Comparative Studies in Society and History 33, no. 4 (1991): 695-725.

JACKSON, Jean. "Culture, Genuine and Spurious: The Politics of Indianness in the Vaupés, Colombia." American Ethnologist 22 (1995): 3-27.

KENT, R. K. "Palmares: An African State in Brazil.” Journal of Negro History 6 (1965): 161-75.

KOINONIA. “O Quilombolismo.” Territórios Negros: Informativo de Apoio às Comunidades Negras Rurais do Rio de Janeiro e Espírito Santo 1, no. 2 (2001a): 3.

KOINONIA. “20 de Novembro.” Territórios Negros: Informativo de Apoio às Comunidades Negras Rurais do Rio de Janeiro e Espírito Santo 1, no. 5 (2001b): 3.

LEVINE, Robert A. "Properties of Culture: An Ethnographic View." In SHWEDER, Richard A. and Robert Alan LeVine. Culture Theory: Essays on Mind, Self, and Emotion. Cambridge [Cambridgeshire]; New York: Cambridge University Press, 1984, 67-87.

MAGNO DA SILVA, Rosemiro. A Luta dos Posseiros de Santana dos Frades. Aracaju: Editora UFS, 2000, 397 p.

MELO, Floro de Araújo. O Folclore Nordestino em Suas Mãos (Síntese de Toda Uma Região). 1st ed. Rio de Janeiro: N/A, 1982.

MENDOZA, Zoila S. Shaping Society through Dance: Mestizo Ritual Performance in the Peruvian Andes. Chicago: University of Chicago Press, 2000, 285 p.

MERRY, Sally Engle. Colonizing Hawai'i: The Cultural Power of Law. Princeton, NJ: Princeton University Press, 2000, 371 p.

MOONEY, Carolyn J. "Anthropologists Shed Light on Jungle Communities Founded by Fugitive Slaves." Chronicle of Higher Education 1998, B2.

MOORE, Sally Falk. Law as Process: An Anthropological Approach. London: Routledge and Kegan Paul, 1978, 270 p.

OLIVEIRA FILHO, João Pacheco de. "Os Instrumentos de Bordo: Expectativas e Possibilidades do Trabalho do Antropólogo em Laudos Periciais.” In SAMPAIO SILVA, 
Orlando, Lídia Luz and Cecília Maria Helm. A Perícia Antropológica em Processos Judiciais, Florianópolis: Editora da UFSC, 1994, 115-39.

QUEIROZ, Maria Isaura Pereira de. O Campesinato Brasileiro: Ensaios sobre Civilização e Grupos Rústicos no Brazil. 2a ed. Petrópolis: Editora Vozes Ltda., 1976, 242 p.

RAMOS, Artur. “O Auto dos Quilombos.” Revisto do Instituto Arquelógico, Histórico e Geográfico Pernambucano 37 (1942): 202-07.

RAPPAPORT, Joanne. Cumbe Reborn: An Andean Ethnography of History. Chicago: University of Chicago Press, 1994, 245 p.

SAHLINS, Marshall. "Two or Three Things That I Know About Culture.” Journal of the Royal Anthropological Institute 5, no. 3 (1999): 399-421.

SANTOS, Boaventura de Sousa. "Law, State and Urban Struggles in Recife, Brazil." Social and Legal Studies 1 (1992): 235-55.

SCHWARTZ, Stuart B. Slaves, Peasants, and Rebels: Reconsidering Brazilian Slavery. Urbana and Chicago: University of Illinois Press, 1992, 174 p.

STARR, June, and Jane F. Collier, eds. History and Power in the Study of Law: New Directions in Legal Anthropology. Ithaca: Cornell University Press, 1989, 377 p.

THOMPSON, E.P. Whigs and Hunters: The Origin of the Black Act. New York: Pantheon Books, 1975, 313 p.

TWINE, France Winddance. Racism in a Racial Democracy: The Maintenance of White Supremacy in Brazil. New Brunswick: Rutgers University Press, 1998, 175 p.

VOGT, Carlos, and Peter Fry. Cafundó: A África no Brasil. Sao Paulo: Ed. da Unicamp, Companhia das Letras, 1996, 373 p.

WARREN, Jonathan W. Racial Revolutions: Antiracism and Indian Resurgence in Brazil, Latin America Otherwise. Durham and London: Duke University Press, 2001, 363p.

WARREN, Kay. "Transforming Memories and Histories: The Meanings of Ethnic Resurgence for Mayan Indians." In STEPAN, Alfred. Americas: New Interpretive Essays. New York: Oxford University Press, 1992, pp. 189-219. 